Информация об авторах

Мещеряков Максим Павлович, кандидат технических наук, доцент кафедры "Прикладная геодезия, природообустройство и водопользование" федерального государственного бюджетного образовательного учреждения высшего образования «Волгоградский государственный аграрный университет» (400002, Россия, г. Волгоград, пр. Университетский, д. 26.), E-mail: makc-sln@yandex.ru.

Болотин Дмитрий Алексадрович, научный сотрудник отдела оросительных мелиораций ФГБНУ Всероссийский научно-исследовательский институт орошаемого земледелия (400002, Россия, г. Волгоград, ул. Тимирязева, 9), E-mail: da.bolotin@yandex.ru.

Мещерякова Елена Геннадьевна, ассистент кафедры "Прикладная геодезия, природообустройство и водопользование" федерального государственного бюджетного образовательного учреждения высшего образования «Волгоградский государственный аграрный университет» (400002, Россия, г. Волгоград, пр. Университетский, д. 26), E-mail: alesn@yandex.ru.

Веденеева Варвара Александровна, кандидат сельскохозяйственных наук, научный сотрудник лаборатории прогнозирования биопродуктивности агролесоландшафтов Федерального научного центра агроэкологии, комплексных мелиораций и защитного лесоразведения РАН (400062, Россия, г. Волгоград, пр-т Университетский, 97), ORCID: https://orcid.org/ 0000-0002-6623-6062, E-mail: vedeneeva-v@vfanc.ru.

\title{
THEORY AND DIGITAL TECHNOLOGIES OF INTELLECTUAL SUPPORT FOR DECISION-MAKING TO INCREASE THE BIO-PRODUCTIVITY OF AGROEKOSYSTEMS BASED ON NEURAL NETWORK MODELS
}

\author{
K.E. Tokarev, A.Yu. Rudenko, V.A. Kuzmin, A.N. Chernyavsky \\ Volgograd State Agrarian University
}

Received 22.04.2021

Submitted 28.11.2021

Acknowledgments: The reported study was funded by RFBR, project number 20-116-50027

\begin{abstract}
Introduction. According to the «Strategy for Scientific and Technological Development of the Russian Federation» and within the framework of the «Digital Agriculture» program, in the coming years, one of the priority areas of development is the transition to a highly productive agricultural and aquaculture industry. The main direction of scientific and technological development in agriculture is to increase the biological productivity of agroecosystems through the development and implementation of intelligent decision support systems that implement neural network models that reflect real processes of crop cultivation. The relevance of the authors' scientific review of methods, algorithms and digital technologies implemented on the basis of neural networks is due to the systematization of approaches to increasing the biological productivity of agricultural systems based on operational monitoring of crops using satellite and unmanned aerial vehicle images. The purpose of the work is to review domestic and foreign scientific research in the field of intellectual decision support to increase the productivity of agricultural production based on neural network models, as well as present the results of our own software developments. Materials and methods. The authors carried out a structural-semantic analysis and synthesis of classical and modern approaches to increasing the productivity of agroecosystems, based on the mathematical and instrumental apparatus of neural networks and intelligent decision support. Results and conclusions. The results of the work of the developed software systems (Programs for EFM No. 2019665010, 2020663063, 2020666192, 2020663315) are presented for intelligent decision support based on multilayer neural networks, deep machine learning methods, computer vision and digital technologies that allow real-time monitoring of crops using satellite and, obtained from unmanned aerial vehicles, aerial photographs. The results obtained can be used to construct hybrid neural network models of a modified architecture for solving problems of operational monitoring of agrocenosis in real time.
\end{abstract}

Key words: digital agriculture, precision agriculture, artificial intelligence, neural network models, agroecosystem, environmental standards. 
Citation. Tokarev K.E., Rudenko A.Yu., Kuzmin V.A., Chernyavsky A.N. Theory and digital technologies of intellectual support for decision-making to increase the bio-productivity of agroecosystems based on neural network models. Proc. of the Lower Volga Agro-University Comp. 2021. 4(64). 421 440 (in Russian). DOI: 10.32786/2071-9485-2021-04-42.

Author's contribution. All authors of this research paper have directly participated in the planning, execution, or analysis of this study. All authors of this paper have read and approved the final version submitted.

Conflict of interest. The authors declare no conflict of interest.

УДК 631.67:004.9

\section{ТЕОРИЯ И ЦИФРОВЫЕ ТЕХНОЛОГИИ ИНТЕЛЛЕКТУАЛЬНОЙ ПОДДЕРЖКИ ПРИНЯТИЯ РЕШЕНИЙ ДЛЯ УВЕЛИЧЕНИЯ БИОПРОДУКТИВНОСТИ АГРОЭКОСИСТЕМ НА ОСНОВЕ НЕЙРОСЕТЕВЫХ МОДЕЛЕЙ}

К. Е. Токарев, кандидат экономических наук, доцент

А. Ю. Руденко, кандидат экономических наук, доцент

В. А. Кузьмин, кандидат экономических наук, преподаватель

А. Н. Чернявский, ассистент

Волгоградский государственный аграрный университет, г. Волгоград

Дата поступления в редакцию 22.04.2021

Дата принятия 28.11.2021

\section{Исследование выполнено при финансовой поддержке РФФИ в рамках научного проекта № 20-116-50027}

Актуальность. Согласно «Стратегии научно-технологического развития Российской Федерации» и в рамках реализации программы «Цифровое сельское хозяйство» в ближайшие годы одним из приоритетных направлений развития будет переход к высокопродуктивному агро-аквахозяйству. Магистральным направлением научно-технического развития в сельском хозяйстве является повышение биопродуктивности агроэкосистем на основе разработки и внедрения интеллектуальных систем поддержки принятия решений реализующих нейросетевые модели, отображающие реальные процессы возделывания культур. Актуальность проводимого авторами научного обзора методов, алгоритмов и цифровых технологий, реализованных на основе нейронных сетей, обусловлена систематизацией подходов к повышению биопродуктивности агросистем на основе оперативного мониторинга посевов с использованием спутниковых и полученных с беспилотных летательных аппаратов снимков. Цель работы провести обзор отечественных и зарубежных научных исследований в области интеллектуальной поддержки принятия решений для повышения продуктивности сельскохозяйственного производства на основе нейросетевых моделей, а также представить результаты собственных программных разработок. Методы. Авторами осуществлен структурно-семантический анализ и синтез классических и современных подходов к повышению продуктивности агроэкосистем, базирующихся на математическом и инструментальном аппаратах нейросетей и интеллектуальной поддержки принятия решений. Результаты. Представлены результаты работы разработанных программных комплексов (Программы для ЭФМ № 2019665010, 2020663063, $2020666192,2020663315)$ для интеллектуальной поддержки принятия решений на основе многослойных нейросетей, методов глубокого машинного обучения, компьютерного зрения и цифровых технологий, позволяющих осуществлять оперативный мониторинг посевов с использованием спутниковых и, полученных с беспилотных летательных аппаратов (БПЛА) аэрофотоснимков. Полученные результаты могут использоваться для построения гибридных нейросетевых моделей модифицированной архитектуры для решения задач оперативного мониторинга агроценоза в режиме реального времени.

Ключевые слова: иифровое сельское хозяйство, точное земледелие, искусственный интеллект, нейросетевые модели, аргоэкосистемы. 
Цитирование. Токарев К. Е., Руденко А. Ю., Кузьмин В. А., Чернявский А. Н. Теория и цифровые технологии интеллектуальной поддержки принятия решений для увеличения биопродуктивности агроэкосистем на основе нейросетевых моделей. Известия $H B A У K$. 2021. 4(64). 421 440. DOI: 10.32786/2071-9485-2021-04-42.

Авторский вклад. Все авторы настоящего исследования принимали непосредственное участие в планировании, выполнении или анализе данного исследования. Все авторы настоящей статьи одобрили представленный окончательный вариант.

Конфликт интересов. Авторы заявляют об отсутствии конфликта интересов.

Введение. В настоящее время одним из наиболее перспективных направлений увеличения биопродуктивности агросистем, связанных с повышением плодородия почв, ресурсосбережением и соблюдением экологических норм, является использование цифровых технологий и интеллектуальных систем поддержки принятия решений в рамках программируемого управления агропроизводством на основе нейронных сетей. Развитие методов и алгоритмов глубокого машинного обучения позволило широко внедрять системы искусственного интеллекта в различные отрасли народного хозяйства, в том числе сельское хозяйство. Согласно «Стратегии научно-технологического развития Российской Федерации» и в рамках реализации программы «Цифровое сельское хозяйство» в ближайшие годы одним из приоритетных направлений развития будет переход к высокопродуктивному агро-аквахозяйству [9, 26, 46,50].

Актуальность обзора теории и цифровых технологий повышения биопродуктивности агроэкосистем обусловлена тем, что методы математического и нейросетевого моделирования, поддержки принятия решений являются важнейшим направлением исследований в области создания интеллектуальных систем в сельском хозяйстве. Переход на новый технологический уклад агропромышленного комплекса невозможен без создания систем, основанных на знаниях, математических моделях и соответствующих программных комплексов.

Повышение плодородия почв связано с решением комплекса взаимоувязанных проблем, базовой из которых является отсутствие системного междисциплинарного подхода к анализу и планированию развития сложных агросистем. Другой проблемой является необходимость повышения плодородия почв при строгом соблюдении экологических норм и ограничений.

Прогрессивные сельхозпроизводители, использующие современные инструменты для сбора данных, имеют несколько тысяч точек сбора данных на полях. Однако сложности, возникающие в процессе контроля и управления информационными потоками в течение всего периода вегетации, порождают необходимость создания интеллектуальных систем обработки данных, базирующихся на анализе мультиспектральных данных, полученных с использованием дистанционного мониторинга.

Магистральным направлением построения идентификационных моделей и регуляторов в рамках реализации искусственных нейронных сетей (ИНС) является использование методов эволюционного моделирования, генетических алгоритмов, позволяющих осуществить обучение, тестирование и структурную оптимизацию нейромоделей. Переход на новый технологический уклад агропромышленного комплекса невозможен без создания систем, основанных на знаниях, математических моделях и соответствующих программных комплексов.

Классические подходы к решению задач обработки данных, компьютерного зрения, анализа и сегментации изображений, базирующиеся на глубоком машинном обучении с использованием компьютеризированных систем, рассматривались в работах Churchland P. S. [41], Aleksander I. [43], McCulloch W. S. [33], Винера H. [6], Hebb D. O. [38], Rosenblatt F. [48], Башкирова O. А. [30]. Современные подходы программного 
управления в точном земледелии с использованием цифровых технологий исследовались Соловьевым Д. А. [18], Cheng G. и Bian, X., Cheng Т. [31-32, 45], Трухачевым В. И. [35] Аксеновым А. Г. [1], Russello Н. [39], Тимошиным В. Н. [15] и др.

Проблемы мониторинга состояния агрофитоценозов в режиме онлайн с использованием компьютеризированных технологий нейросетевого анализа и сегментации снимков высокого разрешения, полученных преимущественно средствами дистанционного зондирования и аэросъемки, рассмотрены в научных трудах Захарова Р. В. [11], Николенко С. [20], Рогачева А. Ф. [23, 24, 44, 47], Сулейманова С. Р. [25], Юна Г. Н [29], Трухачева В. И. [35], Михайленко И. М. [16, 17] и др.

Исследование проблем повышения биопродуктивности на основе оценки воздействия почвенно-климатических и агрометеорологических факторов с использованием инструментальных средств обработки спектральных изображений с беспилотных летальных аппаратов позволило сформулировать задачу мультиклассового распознавания и сегментации аэрофотоснимков для повышения продуктивности агроценозов, которая рассмотрена в работах Заводчикова Н. Д. [10], Гудфеллоу Я. [8], Каширина И. Л. [14], Чжана С. [51], Кругликова С. [40].

Проблемы управления программируемым аграрным производством на примере многолетних ретроспективных данных урожайности сельскохозяйственных культур в сложных условиях с использованием нейросетевой системы рассмотрены в работах Бородычева В. В. [27], Заводчикова Н. Д., Спешиловой Н. В., Таспаева С. С. [10], Мелиховой Е. В. [7, 24], Михайленко И. М. [16], Кашириной И. Л., Демченко М. В. [14] и др.

Вопросами использования систем компьютерного зрения на основе геоинформационного мониторинга с дальнейшим распознаванием искусственными нейронными сетями занимались А. А. Воронцов [12], Череватова Т. Ф., Ермолаева О. С. [28], Алферьев Д. А. [2], Булкина В. И. [4, 5]. Исследования Железновой С. В. [19], Князь В. В. [13], Долженко В. А. [22], Сыч А. С. [21] посвящены анализу аэрофотоснимков посевов сельскохозяйственных культур, сделанных БПЛА с использованием мультиспектральной камеры.

Обзор архитектур нейронных сетей. Искусственные нейронные сети (ИНС) представляют собой компьютерные системы, моделирующие работу биологических нейронов с возможностью осуществления параллельной обработки, способностью к обучению, обобщению информации и накопленных знаний. Развитие методов компьютерного зрения, обработки и сегментации изображений с использованием глубокого машинного обучения обусловлено многообразием архитектур нейронных сетей (таблица 1).

Таблица 1 - Многообразие архитектур нейронных сетей глубокого обучения (составлено авторами)

Table 1 - Diversity of deep learning neural network architectures (compiled by the authors)

\begin{tabular}{|c|c|c|}
\hline $\begin{array}{c}\text { Наименование и способ обуче- } \\
\text { ния / Name and method of training }\end{array}$ & Архитектура / Architecture & Предназначение / Purpose \\
\hline 1 & 2 & 3 \\
\hline $\begin{array}{l}\text { Нейронная сеть Хопфилда, обу- } \\
\text { чение с учителем / Hopfield neu- } \\
\text { ral network, learning with a teacher }\end{array}$ & $\begin{array}{c}\text { Полносвязная сеть с симметрич- } \\
\text { ной матрицей связей / A fully } \\
\text { connectedwork with a symmet- } \\
\text { ric connection matrix }\end{array}$ & $\begin{array}{c}\text { Используется для восстановле- } \\
\text { ния изображений, решения за- } \\
\text { to restore images, solve optimiza- } \\
\text { tion problems, etc. }\end{array}$ \\
\hline $\begin{array}{l}\text { Рекурсивная сеть, стохастиче- } \\
\text { ский метод градиентного спуска }\end{array}$ & Бинарное дерево / Binary Tree & $\begin{array}{c}\text { Анализ данных переменной } \\
\text { длины, обработка естественного } \\
\text { языка (NLP) / Variable-length } \\
\text { data analysis, natural language } \\
\text { processing (NLP) }\end{array}$ \\
\hline
\end{tabular}


Окончание таблицы 1

\begin{tabular}{|l|}
\hline \multicolumn{1}{|c}{1} \\
\hline Сети Элмана и Джордана / Re- \\
cursive network, a stochastic gra- \\
dient descent method Elman and \\
Jordan Networks
\end{tabular}

Машина Больцмана, обучение

по внутренним представлениям («без учителя») / Boltzmann machine, learning from internal representations ("without a teacher»)

\section{2}

Трехслойная нейронная сеть с набором контекстных блоков / А three-layer neural network with a set of context blocks

Стохастически-генеративная модификация нейросетпи Хопфилда / Stochastic-generative modification of the Hopfield neural network

Анализ последовательностей в

системах управления движущимися объектами / Sequence analysis in moving object control systems

Решение сложных комбинаторных задач (выделение признаков, классификация, фильтрация признаков, тематическое моделирование / Solving complex combinatorial problems (feature extraction, classification, feature filtering, thematic modeling

Сверточная нейронная сеть, обучение «с учителем» методом обратного распространения ошибки и его модификаций / Convolutional neural network, learning «with a teacher» by the method of backward error propagation and its modifications

Рекуррентная нейронная сети / Recurrent neural network

злы, соединенные между собой связями / Nodes connected by links

Сверточный, субдискретизирующий и полносвязный (выходной) слои / Convolutional, subsampling, and fully connected (output) layers

Решение задач классификации и компьютерного зрения / Solving classification and computer vision problems

Автоматическое дополнение информации, решение задач распознавания / Automatic addition of information, solving recognition problems

Сеть Кохонена (самоорганизующиеся карты) - итерационное обучение «без учителя» / Kohonen network (self-organizing maps) - iterative learning «without a teacher»)

Многослойный персептрон, обучение с учителем и алгоритм обратног распространения ошибки / Multi-layer perceptron, teacher training, and error back propagation algorithm

Автокодировщик («глубокие) нейронные сети) / Auto-encoder («deep» neural networks)

Двумерная топологическая карта из двух слоев: «input» и «output» / Two-dimensional topological map consisting of two layers: «input» and «output»
Кластеризация и предобработка данных / Clustering and data preprocessing
Трехслойная нейронная сеть (входной, выходной и скрытый слои) / Three-layer neural network (input, output, and hidden layers)

Модификация сети прямого распространения / Modification of the direct distribution network

Модификация сети Автокодировщик
Многомерный анализ больших объемов данных / Multidimensional analysis of large amounts of data

Уменьшение размерности многомерных данных в рамках решения задач визуализации /

Reducing the dimension of multidimensional data in the framework of solving visualization problems

Уменьшение размерности данных / Reducing the data dimension

Наиболее перспективным видом искусственных нейронных сетей, используемых для анализа и классификации изображений в виде цифровых снимков высокого разрешения, в том числе полученных с использованием данных дистанционного зондирования и спутникового мониторинга, являются сверточные сети (Convolutional Neural Networks - CNN), относящиеся к третьему поколению нейромоделей. 
Созданная в 1980 году биологически-мотивированная модель «Neocognitron» (рисунок 1) [36], призванная решать задачи трансляционно-инвариантной обработки изображения, предопределила популярность использования CNN в области компьютерного зрения [36, 42].

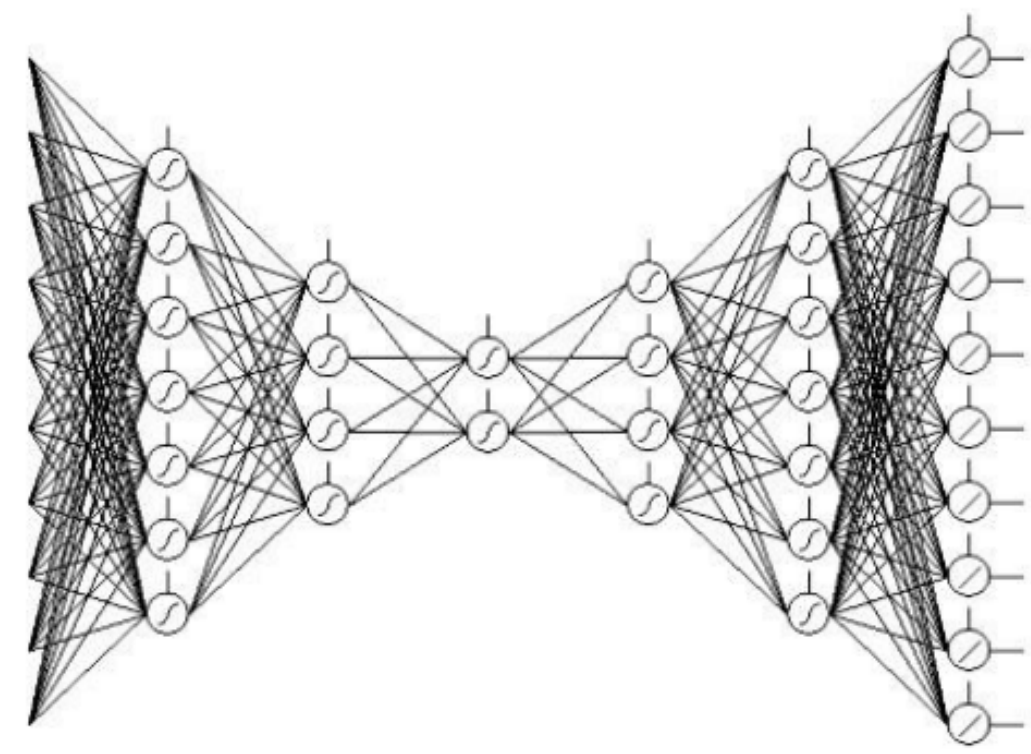

Рисунок 1 - Структура неокогнитрона [36]

Figure 1 - Neocognitron structure [36]

Convolutional Neural Networks классической архитектуры представляют собой многоступенчатый каскад сетей прямого распространения, в структуру функционирования которых входят сверточные слои, слои объединения и слои прямого распространения с обучением. Логическая структура свёрточной сети представлена на рисунке 2.

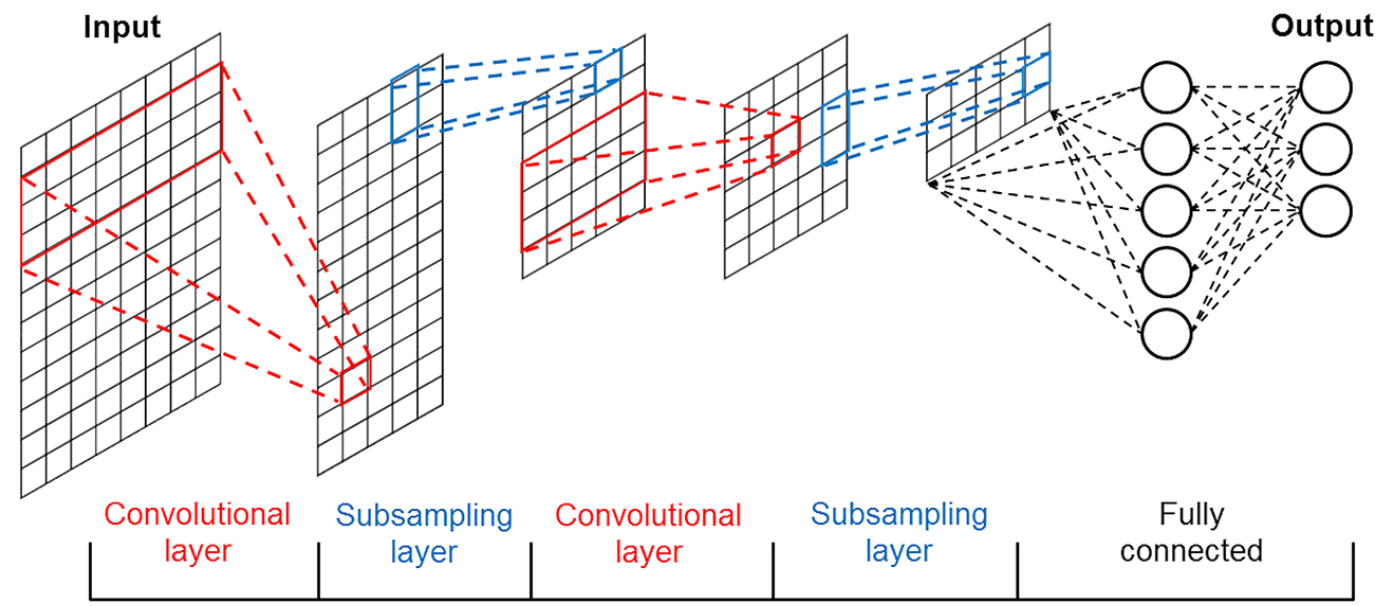

Рисунок 2 - Логическая структура сверточной сети (составлено по материалам $[36,37])$

Figure 2 - Logical structure of the convolutional network (compiled from the materials [36, 37])

Выбор свёрточной нейронной сети обусловлен тем, что на данный момент у данной разновидности нейронных сетей один из лучших алгоритмов распознавания и классификации изображений. По сравнению с полносвязной нейронной сетью у нее гораздо меньшее количество настраиваемых весов. Главной особенностью свёрточной 


\section{***** H3BECTYЯ ***** \\ НИЖНЕВОАЖСКОГО АГРОУНИВЕРСИТЕТСКОГО КОМПАЕКСА: \\ НАУКА И ВЫСШЕЕ ПРОФЕССИОНААЬНОЕ ОБРАЗОВАНИЕ}

нейронной сети является реализация процедур «свёртки», представляющих собой уменьшение размера матрицы признаков изображений, подаваемых на вход сети. Для получения ячейки матрицы уменьшенного размера элементы исходной матрицы в определенной области умножают на вес с последующим суммированием всех элементов в этой области. Чтобы получить следующую ячейку уменьшенной матрицы, происходит сдвиг области и выполнение тех же действий.

В настоящий момент один из лучших алгоритмов решения задач компьютерного зрения в рамках распознавания и классификации изображений реализован в свёрточной модели нейросети. Ключевой особенностью свёрточной модели является реализация процедуры «свертки» для оптимизации размера матрицы признаков подаваемого на вход изображения:

$$
(I * K)=\sum_{i=1}^{h} \sum_{j=1}^{w} K_{i j} \times I_{x+i-1, y+k-1}
$$

где I - исходная матрица признака, $\mathrm{K}$ - матрица весов, $\mathrm{x}, \mathrm{y}$ - индексы выбранного блока, $\mathrm{h}, \mathrm{w}$ высота и ширина.

Пример реализации процедуры «свертки» изображения, поступающего на вход, представлен на рисунке 3 [37].

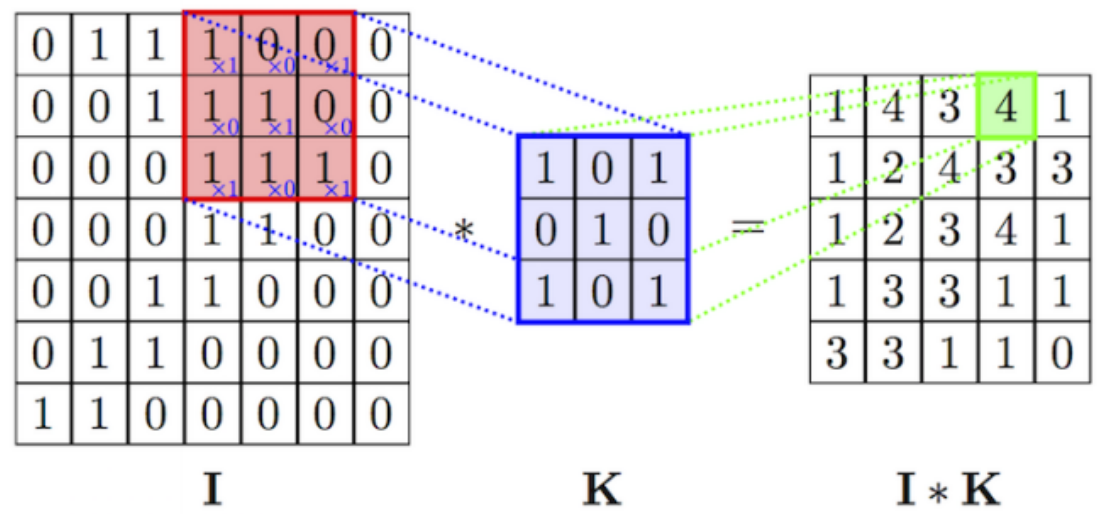

Рисунок 3 - Пример реализации процедуры «свертки» изображения, поступающего на вход [37]

Figure 3 - An example of the implementation of the procedure for «convolution» of the image received at the input [37]

Сверточные нейронные сети глубокого обучения (deep learning $\mathrm{CNN}$ ) благодаря большой емкости сети и динамическим наполнением датасетов изображений продемонстрировали большие возможности в решении задач обработки изображений высокого разрешения, полученных по данным спутникового мониторинга и дистанционного зондирования. Блок-схема процесса обучения нейронной сети для разработанного авторами программного комплекса (Токарев К. Е. и др. Программа для распознавания и визуализации проблемных участков посевов сельскохозяйственных культур по данным спутникового мониторинга и дистанционного зондирования // Свидетельство о регистрации программы для ЭВМ 2020663315, 26.10.2020. Заявка № 2020662046 от 12.10.2020) анализа снимков дистанционного зондирования и спутникового мониторинга представлена на рисунке 4.

В работе [34] предложен алгоритм классификации гиперспектральных изображений, базирующийся на сверточной нейронной сети глубокого обучения из пяти слоев (input-слой, output-слой, сверточный и полносвязный слои, слой «max pooling»). Иссле- 
дование нейромодели на гиперспектральных данных дистанционного мониторинга с размерами областей 512 на 217 пикселей и пространственным разрешением в 20 метров показало высочайшую точность распознавания (более 90 \%). Сверточные нейросети глубокого обучения, обученные на больших датасетах (более 5000 тыс. изображений), были использованы в задачах сегментации зрительных сцен. Предложенные сценарии идентификации глобальных характеристик изображений позволили достичь точности сегментации изображений на уровне 96-98 \% [34].

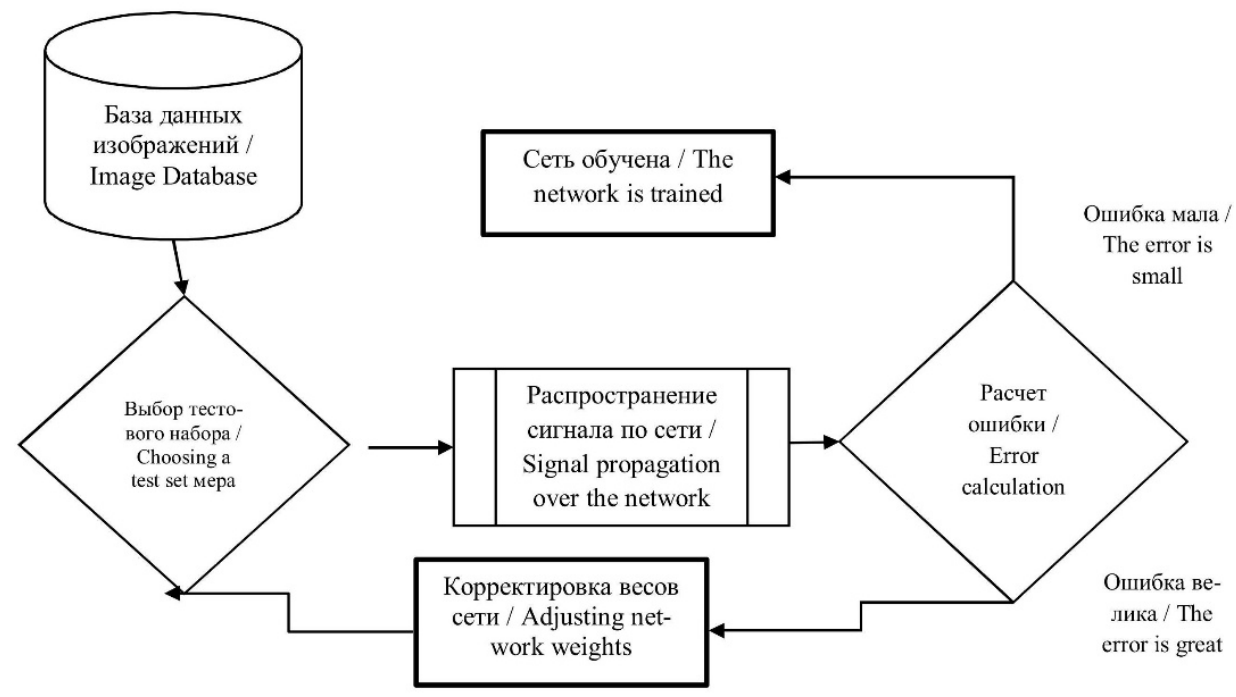

Рисунок 4 - Блок-схема процесса обучения нейронной сети для анализа снимков дистанционного зондирования и спутникового мониторинга (составлена авторами)

Figure 4 - Block diagram of the process of classification of images of agricultural crops and localization of extracted plots (compiled by the authors)

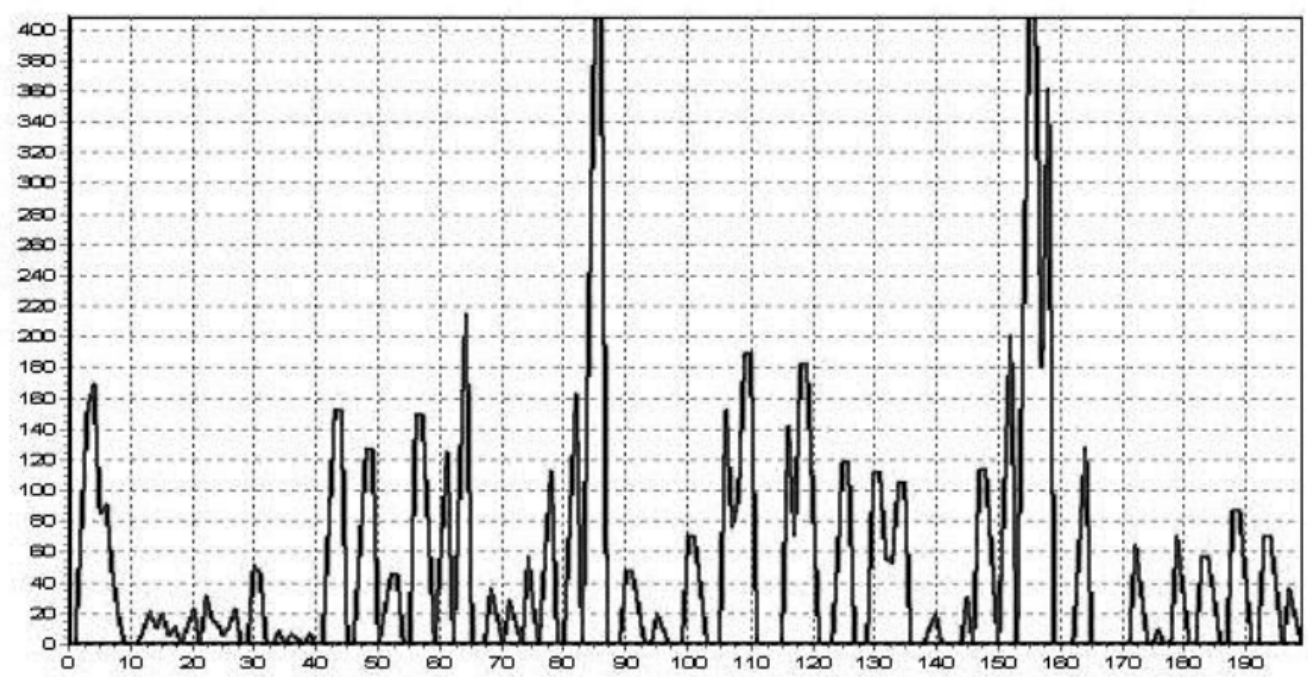

Рисунок 5 - Пример спектра белка пшеницы [52]

Figure 5 - Example of wheat protein spectrum [52]

Подход к использованию CNN глубокого обучения для решения задач классификации сортов пшеницы по денситограммам (рисунок 5), базирующийся на анализе одномерного изображения в виде полосы электрофореграммы после оцифровки пред- 
ставлен в работе [3]. Процедура уменьшения размерности данных методов главных компонент с последующей обработкой глубокой нейронной сетью позволила выделить 64 основных признака для точного восстановления в выходном слое без потери точности после сжатия изображения.

Разработанный авторами алгоритм (рисунок 6) классификации аэрофотоснимков посевов сельскохозяйственных культур, идентификации и анализа их состояния с возможностью локализации экстрагированных участков позволил реализовать программную систему на основе web-интерфейса с возможностью мониторинга посевов в режиме онлайн с использованием мобильных устройств (Токарев К. Е. Кроссплатформенная мобильная система идентификации и анализа состояния посевов сельскохозяйственных культур с WEB-интерфейсом // Свидетельство о регистрации программы для ЭВМ 2021610501, 14.01.2021. Заявка № 2020667401 от 23.12.2020).

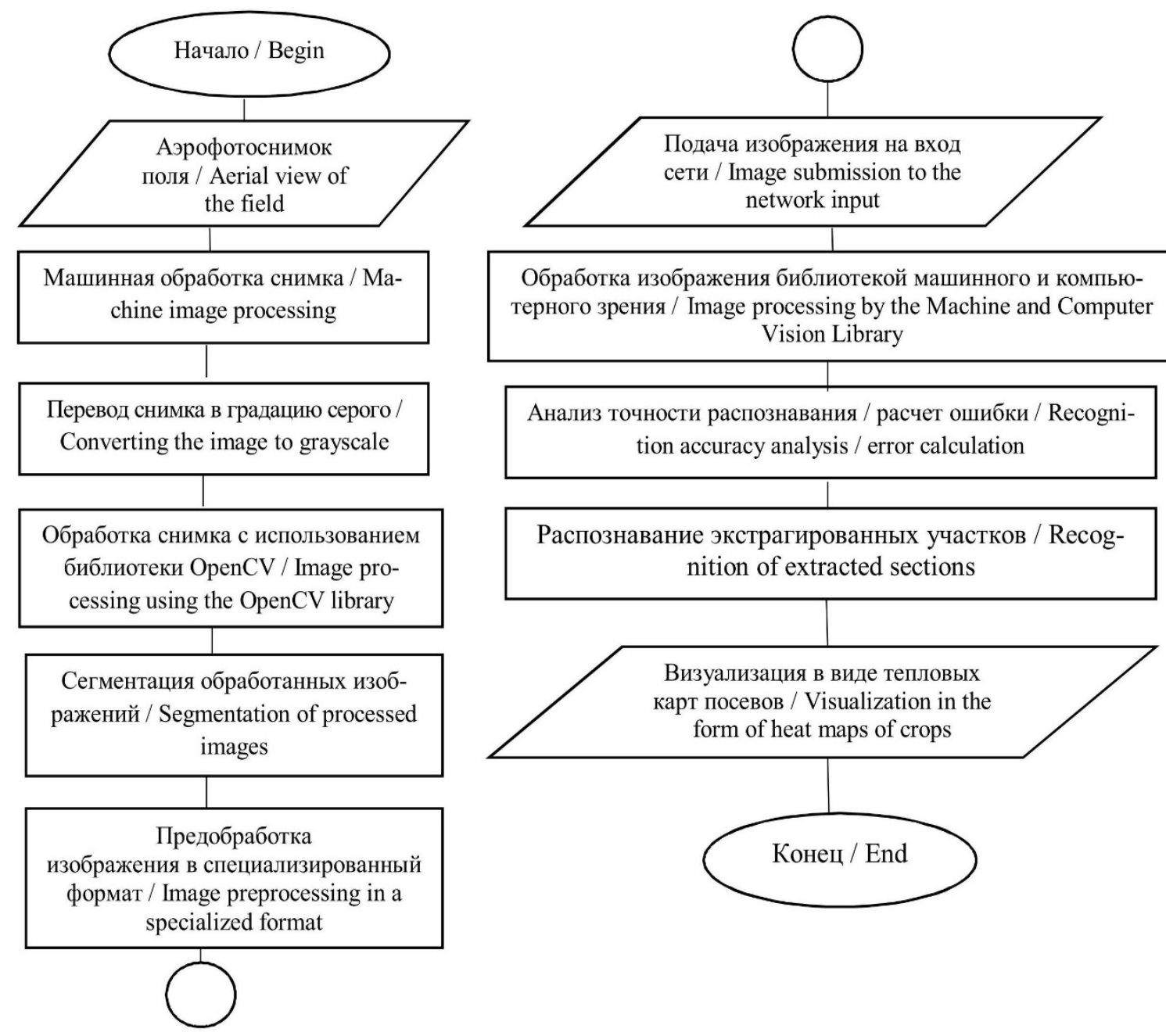

Рисунок 6 - Блок-схема процесса классификации снимков посевов сельскохозяйственных культур и локализации экстрагированных участков (составлена авторами)

Figure 6 - Block diagram of the process of classification of images of agricultural crops and localization of extracted plots (compiled by the authors)

Подходы, развиваемые в этом классе задач, могут оказаться полезными при решении задач восстановления характеристик атмосферы и подстилающей земной поверхности по гиперспектральным спутниковым данным. 


\section{***** HЗВЕСТИЯ ***** \\ НИЖНЕВОАЖСКОГО АГРОУНИВЕРСИТЕТСКОГО КОМПАЕКСА: НАУКА И ВЫСШЕЕ ПРОФЕССИОНААЬНОЕ ОБРАЗОВАНИЕ}

Результаты. В рамках научных исследований сотрудников ФГБОУ ВО Волгоградский ГАУ, посвященных проблемам интеллектуальной поддержки принятия решений для увеличения биопродуктивности агроэкосистем на основе нейросетевых моделей, глубокого машинного обучения, цифровых технологий и реализующих их компьютерных систем при поддержке Российского фонда фундаментальных исследований (Гранты № 19-416-343006; 20-116-50027; 17-12-34-048-ОГН; 18-416-342015 и др.), а также Совета по грантам Президента РФ (МК-592.2020.11), реализован комплекс программных средств [34]:

1. Многослойная нейронная сеть глубокого обучения для анализа аэрофотоснимков сельскохозяйственных культур. Программа предназначена для распознавания, обработки и анализа в качестве объектов идентификации аэрофотоснимков сельскохозяйственных культур на основе использования многослойной нейронной сети глубокого обучения. Использование программного средства возможно для исследования и изучения особенностей возделывания в условиях орошения и дифференцированного размещения (рисунок 7 - Токарев К. Е., Кузьмин В. А., Руденко А. Ю., Процюк М. П. Многослойная нейронная сеть глубокого обучения для анализа аэрофотоснимков сельскохозяйственных культур // Свидетельство о регистрации программы для ЭВМ RU 2019666234, 06.12.2019. Заявка № 2019665010 от 25.11.2019.).

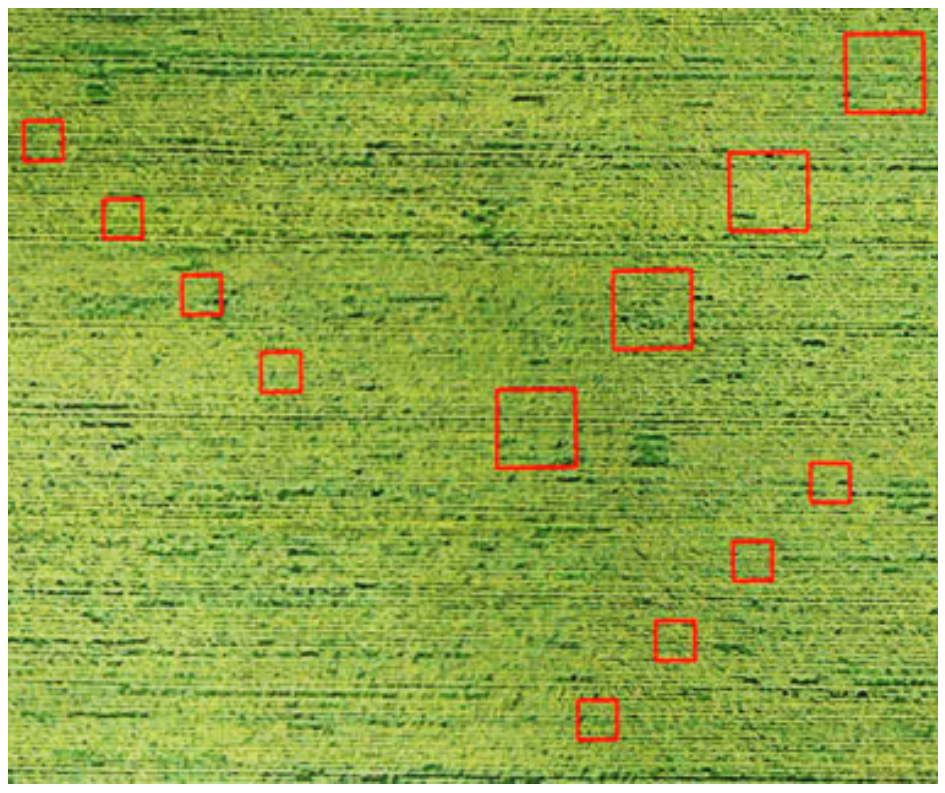

Рисунок 7 - Результат сегментации аэрофотоснимка посевов сельскохозяйственных культур

Figure 7 - The result of segmentation of aerial photographs of agricultural crops

2. Сегментация изображений посевов сельскохозяйственных культур по цифровым аэрофотоснимкам с беспилотных летательных аппаратов. Программа предназначена для обработки и сегментации цифровых аэрофотоснимков посевов сельскохозяйственных культур высокого разрешения, сделанных преимущественно с беспилотных летальных аппаратов, по заданным пользователем параметрам с использованием специализированных библиотек глубокого машинного обучения для последующей обработки искусственными нейронными сетями различных архитектур (рисунок 8 - Токарев К. Е. Программа для сегментации изображений посевов сельскохозяйственных культур по цифровым аэрофотоснимкам с БЛА // Свидетельство о регистрации программы для ЭВМ 2020663063, 22.10.2020. Заявка № 2020662104 от 12.10.2020). 


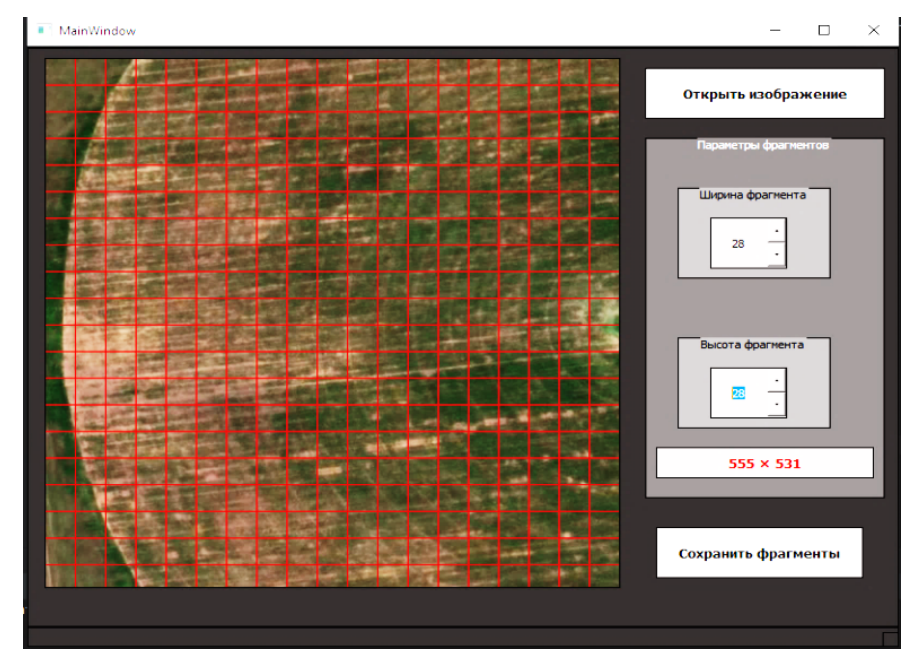

Рисунок 8 - Интерфейс модуля сегментации изображений посевов сельскохозяйственных культур по цифровым аэрофотоснимкам с БЛА

Figure 8 - Interface of the module for segmentation of images of agricultural crops based on digital aerial photographs from UAVs

3. Распознавание и визуализация проблемных участков посевов сельскохозяйственных культур по данным спутникового мониторинга и дистанционного зондирования. Программа предназначена для распознавания и обработки в качестве объектов идентификации данных спутникового мониторинга и дистанционного зондирования в виде цифровых изображений высокого разрешения с использованием специализированных библиотек глубокого машинного обучения и последующей визуализацией результатов в виде тепловых карт посевов сельскохозяйственных культур с сегментированием проблемных участков (рисунок 9 - Токарев К. Е. Кроссплатформенная мобильная система идентификации и анализа состояния посевов сельскохозяйственных культур с WEB-интерфейсом // Свидетельство о регистрации программы для ЭВМ 2021610501, 14.01.2021. Заявка № 2020667401 от 23.12.2020).

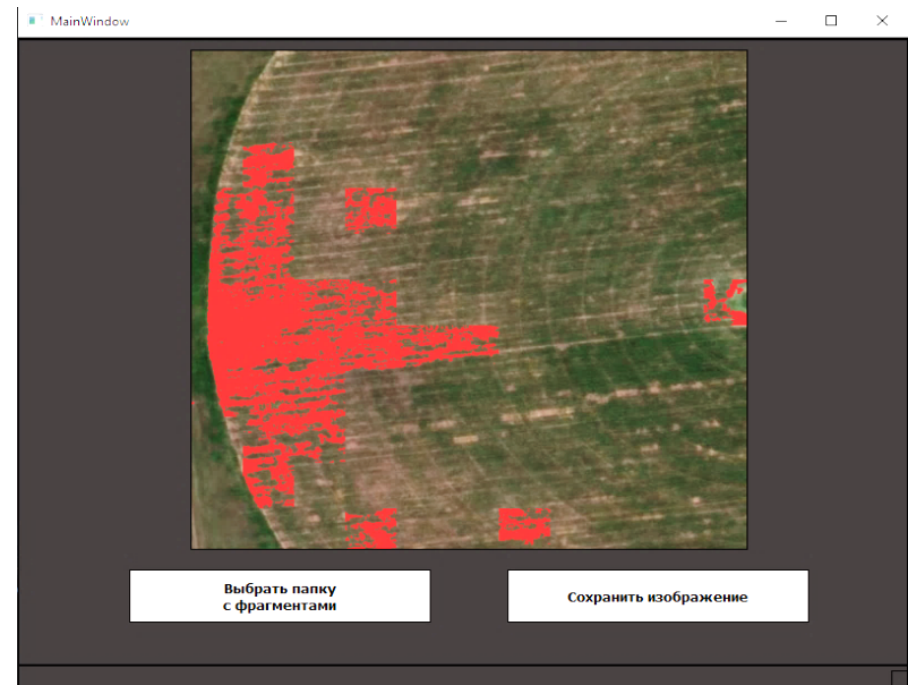

Рисунок 9 - Интерфейс модуля распознавания и визуализации проблемных участков посевов сельскохозяйственных культур по данным спутникового мониторинга и дистанционного зондирования

Figure 9 - Interface of the module for recognizing and visualizing problem areas of agricultural crops based on satellite monitoring and remote sensing data 
4. Оценка водно-физических свойств почв в условиях орошения. Программа предназначена для оценки водно-физических свойств почв в условиях орошения и расчета коэффициента увлажнения по заданным пользователем данным. Область применения программы: сельскохозяйственное производство. Функции программы: оценка воднофизических свойств почв и составление рекомендаций по их оптимизации, расчет коэффициента увлажнения с учетом количества осадков за расчетный период и подекадных значений (рисунок 10 - Токарев К. Е. Программа для расчета режимов орошения и оперативного планирования поливов в режиме реального времени // Свидетельство о регистрации программы для ЭВМ 2020666192, 04.12.2020. Заявка № 2020665251 от 24.11.2020.).

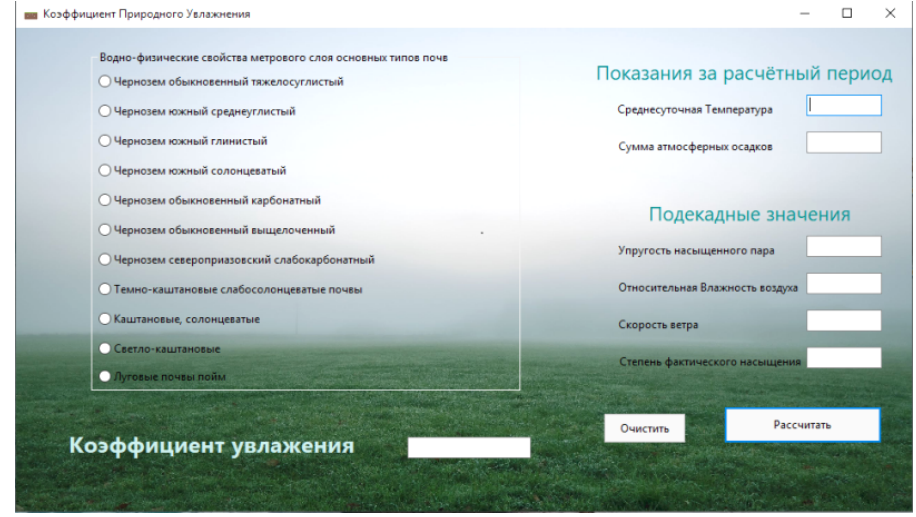

Рисунок 10 - Диалоговое окно модуля расчета коэффициента увлажнения

Figure 10 - Dialog box of the module for calculating the moisture coefficient of the module

5. Кроссплатформенная мобильная система идентификации и анализа состояния посевов сельскохозяйственных культур с WEB-интерфейсом. Кроссплатформенная мобильная система предназначена для идентификации и анализа состояния посевов сельскохозяйственных культур по данным спутникового мониторинга и дистанционного зондирования в виде цветных аэрофотоснимков. Область применения программы: сельскохозяйственное производство. Функции программы: обработка цветных аэрофотоснимков, поиск, обработка и визуализация проблемных участков посевов сельскохозяйственных культур с помощью специализированных библиотек и вегетационных индексов (Рисунок 11 - Токарев К.Е. Кроссплатформенная мобильная система идентификации и анализа состояния посевов сельскохозяйственных культур с WEB-интерфейсом // Свидетельство о регистрации программы для ЭВМ 2021610501, 14.01.2021. Заявка № 2020667401 от 23.12.2020).

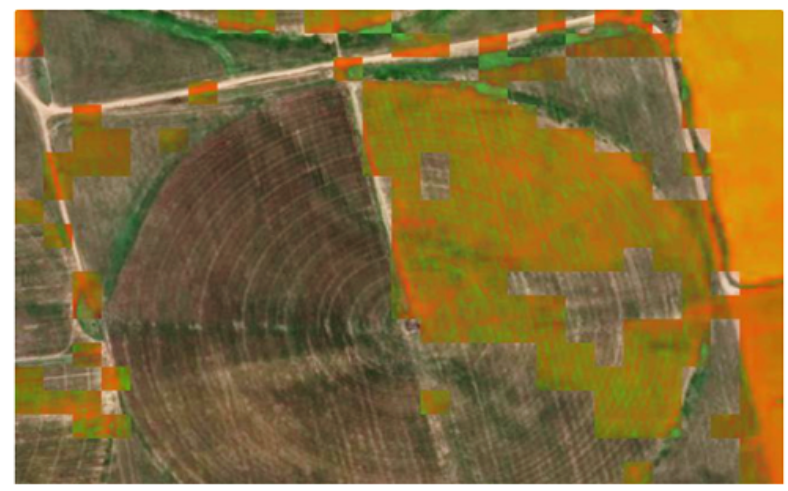

Рисунок 11 - Диалоговое окно визуализации результатов обработки аэрофотоснимка с выделением осушенных участков

Figure 11 - Dialog box for visualizing the results of processing an aerial photo with the selection of drained areas 


\section{***** I3BECTYЯ ***** \\ НИЖНЕВОАЖСКОГО АГРОУНИВЕРСИТЕТСКОГО КОМПАЕКСА: НАУКА И ВЫСШЕЕ ПРОФЕССИОНААЬНОЕ ОБРАЗОВАНИЕ}

6. Нейросетевая классификация состояния посевов сельскохозяйственных культур по цветным изображениям высокого разрешения. Программа предназначена для решения задачи бинарной классификации состояния посевов сельскохозяйственных культур по цветным аэрофотографическим изображениям высокого разрешения с помощью искусственной нейронной сети. Сеть включает сверточные и полносвязные слои. Исходные данные для обучения искусственной нейронной сети группируются в двух директориях. При обучении применена аугментация цветных изображений участков сельскохозяйственных полей (рисунок 12 - Рогачев А. Ф., Мелихова Е. В., Рыжова Т. А., Белоусов И. C. Нейросетевая классификация состояния посевов сельскохозяйственных культур по цветным изображениям высокого разрешения // Свидетельство о регистрации программы для ЭВМ RU 2020611604, 05.02.2020. Заявка № 2019665063 от 25.11.2019).
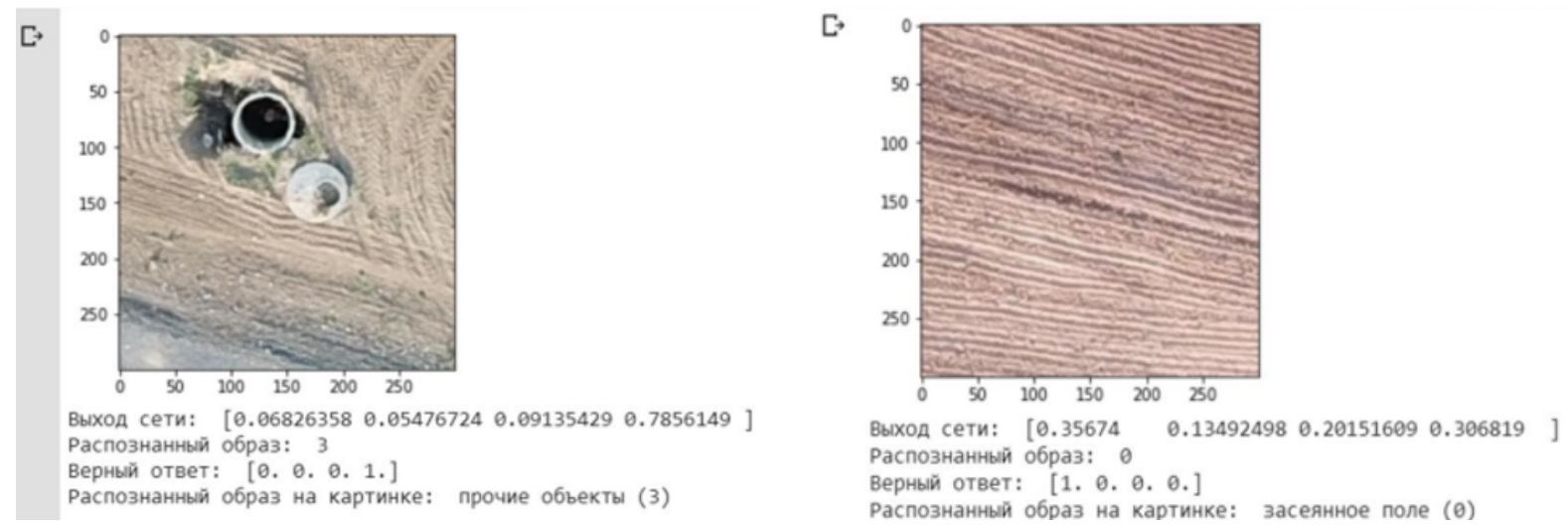

Рисунок 12 - Результаты распознавания тестовых изображений объектов классов «Прочие объекты», «Засеянное поле»

Figure 12 - Results of recognition of test images of objects of the «Other objects» and «Seeded field» classes

7. База данных цветных изображений сельскохозяйственных полей для обучения искусственных нейронных сетей. База данных содержит совокупность цветных изображений участков сельскохозяйственных полей и предназначена для обучения искусственных нейронных сетей для решения задачи классификации состояния посевов сельскохозяйственных культур по изображениям высокого разрешения. Совокупность цветных изображений сгруппирована в двух директориях, соответствующих состоянию анализируемых участков полей, и может использоваться для формирования обучающих, проверочных и тестовых выборок при обучении ИНС. С использованием базы данных в процессе обучения ИНС может быть применена аугментация цветных изображений участков сельскохозяйственных полей (Рогачев А. Ф., Мелихова Е. В., Боровой Е. П. База данных цветных изображений сельскохозяйственных полей для обучения искусственных нейронных сетей // Свидетельство о регистрации базы ных 2020620950, 11.06.2020. Заявка № 2020620840 от 01.06.2020).

Развитие полученных авторами результатов возможно в направлении создания гибридных нейронных сетей модифицированной архитектуры для решения задач оперативного мониторинга агроценоза в режиме реального времени.

Выводы. Проведенный авторами обзор отечественных и зарубежных исследований, а также собственных разработок, посвященных проблемам повышения биопродуктивности с использованием компьютерных систем поддержки принятия решений, реализующих нейросетевые алгоритмы, позволил выделить ключевые проблемы, требующие решения и дальнейшего исследования: 
- обеспечение разработки компьютерных информационно-управляющих систем мониторинга агроценозов в режиме реального времени;

- модернизация цифровых оболочек обработки данных дистанционного мониторинга, интеграция в них облачных технологий, систем обработки больших массивов данных и методов глубокого машинного обучения;

- разработка программных комплексов, реализующих алгоритмы нейросетевого моделирования и компьютерного зрения;

- использование универсальных мобильных телекоммуникационных средств для решения вспомогательных задач сельскохозяйственного производства на основе спутникового мониторинга и дистанционного зондирования;

- разработка программных комплексов мониторинга развития агробиоценозов с учетом почвенно-климатических и агробиологических условий, оснащенных эргономичным Web-интерфейсом;

- совершенствование методов повышения продуктивности земель с.-х. назначения с учетом почвенно-климатических, агроэкологических факторов в условиях мелиорации, базирующихся на оперативных результатах спутникового мониторинга территорий и данных дистанционного зондирования;

- использование данных дистанционного зондирования полученных с использованием беспилотных летательных аппаратов для мониторинга мелиоративного состояния агроценозов в режиме онлайн;

- разработка интеллектуальных моделей и методов обработки информации, учитывающих специфику сохранения земель, ресурсосбережения и повышение уровня воспроизводства сельскохозяйственных культур.

\section{Библиографический список}

1. Аксенов А. Г. Анализ интеллектуальных систем поддержки принятия решений в сельском хозяйстве // Электротехнологии и электрооборудование в АПК. 2019. № 3 (36). С. 46-51.

2. Алферьев Д. А. Практика реализации сверточных нейронных сетей в сельском хозяйстве и агропромышленном комплексе // АгроЗооТехника. 2020. Т. 3. № 2. С. 4.

3. Басс Л. П., Кузьмина М. Г., Николаева О. В. Сверточные нейронные сети с глубоким обучением в задачах обработки гиперспектральных спутниковых данных // Препринты ИПМ им. М.В.Келдыша. 2018. № 282. 32 с.

4. Булкин В. И. Создание интеллектуальных систем в промышленности и сельском хозяйстве на основе управляемого синтеза искусственных нейронных сетей // Промышленность и сельское хозяйство. 2020. № 4 (21). С. 68-75.

5. Булкин В. И. Создание интеллектуальных систем в промышленности и сельском хозяйстве с использованием технологии параллельно-последовательной обработки знаний // Промышленность и сельское хозяйство. 2020. № 11 (28). С. 102-110. $1968.357 \mathrm{c}$.

6. Винер Н. Кибернетика или управление и связь в животном и машине. М.: Сов. радио,

7. Гагарин А. Г., Рогачев А. Ф. Применение искусственных нейронных сетей для прогнозирования урожайности на основе анализа кросс-региональных данных // Известия НВ АУК. 2018. № 2. С. 339-346.

8. Гудфеллоу Я., Бенджио И., Курвилль А. Глубокое обучение. М.: ДМК Пресс, 2018. 652 с.

9. Дубенок Н. Н., Бородычев В. В., Лытов М. Н. Алгоритм учета пространственной неоднородности исходных характеристик орошаемого участка на основе ГИС-технологий // Российская сельскохозяйственная наука. 2019. № 1. С. 66-70.

10. Заводчиков Н. Д., Спешилова Н. В., Таспаев С. С. Использование нейросетевых технологий в прогнозировании эффективности производства зерна // Известия Оренбургского государственного аграрного университета. 2015. № 1 (51). С. 216-219.

11. Захарова Р. В., Гайнутдинов И. Г. Применение беспилотного летательного аппарата при десикации масличных культур // Вектор экономики. 2018. № 11 (29). С. 118. 
12. Зверева В. И., Воронцов А. А. Искусственные нейронные сети и геоинформационные технологии в сельском хозяйстве // Современные инновационные технологии подготовки инженерных кадров для горной промышленности и транспорта. 2019. № 1 (6). С. 191-196.

13. Использование глубоких свёрточных нейронных сетей для автоматического выделения препятствий на взлетно-посадочной полосе по данным видимого и инфракрасного диапазона / В. В. Князь [и др.] // Научная визуализация. 2017. Т. 9. № 4. С. 89-96.

14. Каширина И. Л., Демченко М. В. Исследование и сравнительный анализ методов оптимизации, используемых при обучении нейронных сетей // Вестник ВГУ. Системный анализ и информационные технологии. 2018. № 4. С. 123-132.

15. Михайленко И. М., Тимошин В. Н. Экспертные системы программного управления в точном земледелии // Вестник российской сельскохозяйственной науки. 2020. № 2. С. 11-16.

16. Михайленко И. М. Развитие методов и средств применения данных дистанционного зондирования земли в сельском хозяйстве // Тенденции развития науки и образования. 2018. № 41-3. С. 70-83.

17. Михайленко И. М. Управление агротехнологиями и роботизированные и роботизированные средства реализации // Инновации в сельском хозяйстве. 2019. № 1 (30). С. 242-258.

18. Моделирование нейроуправления скоростью дождевальных машин / Д. А. Соловьев [и др.] // Аграрный научный журнал. 2020. № 7. С. 81-84.

19. Мониторинг посевов озимой пшеницы с применением беспилотной аэрофотосъемки и оптического датчика GreenSeeker RT200 / С. В. Железова [и др.] // Вестник Оренбургского государственного университета. 2016. № 6. С. 56-61.

20. Николенко С., Кадурин А., Архангельская Е. Глубокое обучение. СПб.: Питер, 2018. $480 \mathrm{c}$.

21. Применение аэрофотосъёмки с применением мультиспектральной камеры в комплексе с нейросетью в сельском хозяйстве / А. С. Сыч [и др.] // Chronos. 2019. № 9 (36). С. 26-28.

22. Применение мультиспектральной аэрофотосъёмки в комплексе с нейросетью для автоматизации мониторинга в сельском хозяйстве / В. А. Долженко [и др.] // Наукоемкие технологии и инновации (XXIII научные чтения): сборник докладов Международной научнопрактической конференции, посвященной 65-летию БГТУ им. В. Г. Шухова. 2019. С. 33-37.

23. Рогачев А. Ф. Мелихова Е. В., Белоусов И. С. Исследование развития и продуктивности сельскохозяйственных культур с применением беспилотных летательных аппаратов // Известия НВ АУК. 2020. № 3 (59). С. 397-406.

24. Рогачев А. Ф., Мелихова Е. В. Обоснование алгоритмов и инструментария для нейросетевого прогнозирования урожайности агрокультур с использованием ретроспективных данных // Известия НВ АУК. 2020. №1. С. 290-302.

25. Сулейманов С. Р., Логинов Н. А. Перспектива использования дистанционного зондирования земли и БПЛА в сельском хозяйстве Татарстана // Вестник Казанского государственного аграрного университета. 2017. Т. 12. № 4 (46). С. 17-19.

26. Теория и технологии управления орошением сельскохозяйственных культур на основе информационных технологий поддержки принятия решений и математического моделирования / К. Е. Токарев [и др.] // Известия НВ АУК. 2020. № 4 (60). С. 433-448.

27. Факторный анализ данных по урожайности раннего картофеля в полевом опыте и обработка результатов имитационного моделирования / В. В. Бородычев [и др.] // Известия НВ АУК. 2020. № 2 (58). С. 404-419.

28. Череватова Т. Ф., Ермолаева О. С. Искусственный интеллект: диагностика болезней растений по распознаванию изображений // Экономика и предпринимательство. 2021. № 2 (127). С. 980-985.

29. Юн Г. Н., Мединский Д. В. Применение беспилотных летательных аппаратов в сельском хозяйстве // Наукоємні технології. 2017. Т. 36. № 4. С. 35-41.

30. Bashkirov O. A., Bravermann E. M., Muchnik I. B. Potential function algorithms for pattern recognition learning machines // Automation and Remote Control. - 1964. - N 25. - P. 629-631.

31. Bian, X., Chen, C. Fusing local and global features for high-resolution scene classification // IEEE J. Sel. Topics Appl. Earth Observ. Remote Sens. 2017. V. 10 (6). P. 2889-2901. 


\section{***** Y3BECTYЯ ***** \\ НИЖНЕВОАЖСКОГО АГРОУНИВЕРСИТЕТСКОГО КОМПАЕКСА: \\ НАУКА И ВЫСШЕЕ ПРОФЕССИОНААЬНОЕ ОБРАЗОВАНИЕ}

32. Cheng G., Li Z. Remote sensing image scene classification using bag of convolutional features // IEEE Geosci. Remote Sensing Lett. 2017. V. 14 (10). P. 1735-1739.

33. Chlingaryan A., Sukkarieh S., Whelan B. Machine learning approaches for crop yield prediction and nitrogen status estimation in precision agriculture: A review // Comput. Electron. Agricult. 2018. Vol. 151. P. 61-69.

34. Deep convolutional neural networks for hyperspectral image classification / W. Hu [et al.] // Journal of Sensors. 2015. V. 2015. No. 258619.

35. Estimation of condition of cultivated pastures under remote sensing of earth / V. I. Trukhachev // Engineering for Rural Development Proceedings. 2019. P. 442-449.

36. Fukushima K. Neocognitron: A self-organizing neural network model for a mechanism of pattern recognition unaffected by shift in position // Biol. Cybern. 1980. V. 36. No. 4. P. 193-202.

37. Goodfellow I. Deep Learning (Adaptive Computation and Machine Learning series) // The MIT Press. 2016. Nov. P. 800.

38. Hebb D. O. The Organization of Behavior: A Neuropsychological Theory. New York: Wiley, 1949. $358 \mathrm{p}$.

39. Kadhim V. A., Abed M. H. Convolutional Neural Network for Satellite Image Classification // Studies in Computational Intelligence. 2020 P. 165-178.

40. Kitonsa H., Kruglikov S. V. Significance of drone technology for achievement of the united nations sustainable development goals // R-Economy. 2018. V. 4. № 3. P. 115-120.

41. Khaki, Wang L. Crop yield prediction using deep neural networks // Frontiers Plant Sei. 2019. Vol. 10. P. 621.

42. Krizhevsky A., Sutskever I., and Hinton G., Imagenet classification with deep convolutional neural networks // Advances in Neural Information Processing Systems (NIPS). Lake Tahoe. NV, USA, 2012. P. 1097-1105.

43. Machine learning in agriculture: A review / K. G. Liakos [et al.] // Sensors. 2018. Vol. 18. No. 8. P. 2674.

44. Melikhova E.V. Information system and database for simulation of irrigated crop growing / Melikhova E.V., Rogachev A.F., Skiter N.N. // Studies in Computational Intelligence. 2019. T. 826. P. 1185-1191.

45. Recent Advances in Remote Sensing for Crop Growth Monitoring [Tekst] / Cheng, T.; Yang, Z.; Inoue, Y.; Zhu, Y.; Cao, W. Preface // Remote Sens. - 2016. -№ 8. - P. 116.

46. Review of modern technologies intellectual decision support in the reclamation of agricultural crops / Tokarev K.E., Nekrasova T.N., Popova O.V., Lebed N.I. // IOP Conference Series: Earth and Environmental Science. 2. Cep. "Mathematical Modeling of Technical and Economic Systems in Agriculture II" 2020. P. 012023.

47. Rogachev A. F., Melikhova E. V., Shokhnekh A. V. Monitoring and economic \& mathematical modeling of manufacture and consumption of agricultural products as a tool of food security management // Espacios. 2018. V. 39. № 1. P. 1.

48. Rosenblatt F. The Perceptron: A probabilistic model for information storage and organization in the brain // Psychological Review. 1958. N 65. P. 386-408.

49. Simonyan K., Vedaldi A., Zisserman A. Deep inside convolutional networks: visualizing image classification models and saliency maps. arXiv preprint arXiv:1312.6034, 2013.

50. Vegetative indices dynamics modeling based on multispectral distant monitoring data analysis / Tokarev K.E. // IOP Conference Series: Earth and Environmental Science. 3. Cep. "Mathematical Modeling of Technical and Economic Systems in Agriculture III-2020" 2021. P. 012038.

51. Understanding deep learning requires rethinking generalization/ C. Zhang, S. Bengio, M. Hardt, B. Recht, O. Vinyals // Cornell University Library. 2016.

Conclusions. The authors ' review of domestic and foreign studies, as well as their own developments, devoted to the problems of increasing bioproductivity using computer decision support systems implementing neural network algorithms, allowed us to identify key problems that require solutions and further research:

- ensuring the development of computer information and control systems for monitoring agrocenoses in real time; 
- modernization of digital remote monitoring data processing shells, integration of cloud technologies, large data processing systems and deep machine learning methods into them;

- development of software systems that implement algorithms for neural network modeling and computer vision;

- the use of universal mobile telecommunications tools for solving auxiliary tasks of agricultural production based on satellite monitoring and remote sensing;

- development of software complexes for monitoring the development of agrobiocenoses, taking into account soil-climatic and agrobiological conditions, equipped with an ergonomic Web interface,

- improvement of methods for increasing the productivity of agricultural lands, taking into account soil-climatic, agroecological factors in the conditions of land reclamation, based on the operational results of satellite monitoring of territories and remote sensing data;

- the use of remote sensing data obtained using unmanned aerial vehicles to monitor the reclamation state of agrocenoses online;

- development of intelligent models and methods of information processing that take into account the specifics of land conservation, resource conservation and increasing the level of reproduction of agricultural crops.

Bio-productivity of agricultural systems based on operational monitoring of crops using satellite and images obtained from unmanned aerial vehicles. The purpose of this work is to review domestic and foreign scientific developments in the field of intellectual decisionmaking support for increasing agricultural productivity based on neural network models, as well as to present the results of their own software developments.

\section{References}

1. Aksenov A. G. Analiz intellektual'nyh sistem podderzhki prinyatiya re-shenij v sel'skom hozyajstve // Jelektrotehnologii i ]lektrooborudovanie v APK. 2019. № 3 (36). P. 46-51.

2. Alfer'ev D. A. Praktika realizacii svertochnyh nejronnyh setej v sel'skom hozyajstve i agropromyshlennom komplekse // AgroZooTehnika. 2020. V. 3. № 2. P. 4.

3. Bass L. P., Kuz'mina M. G., Nikolaeva O. V. Cvertochnye nejronnye seti c glubokim obucheniem v zadachah obrabotki giperspektral'nyh sputnikovyh dannyh // Preprinty IPM im. M. V. Keldysha. 2018. № 282. 32 p.

4. Bulkin V. I. Sozdanie intellektual'nyh sistem v promyshlennosti i sel'skom hozyajstve na osnove upravlyaemogo sinteza iskusstvennyh nejronnyh setej // Promyshlennost' i sel'skoe hozyajstvo. 2020. № 4 (21). P. 68-75.

5. Bulkin V. I. Sozdanie intellektual'nyh sistem v promyshlennosti i sel'skom hozyajstve s ispol'zovaniem tehnologii parallel'no-posledovatel'noj obra-botki znanij // Promyshlennost' i sel'skoe hozyajstvo. 2020. № 11 (28). P. 102-110.

6. Viner N. Kibernetika ili upravlenie i svyaz' v zhivotnom i mashine. M.: Sov. radio, 1968. 357 p.

7. Gagarin A. G., Rogachev A. F. Primenenie iskusstvennyh nejronnyh setej dlya prognozirovaniya urozhajnosti na osnove analiza kross-regional'nyh dannyh // Izvestiya NV AUK. 2018. № 2. P. 339-346.

8. Gudfellou Ya., Bendzhio I., Kurvill' A. Glubokoe obuchenie. M.: DMK Press, 2018. 652 p.

9. Dubenok N. N., Borodychev V. V., Lytov M. N. Algoritm ucheta prostran-stvennoj neodnorodnosti isxodnyh harakteristik oroshaemogo uchastka na osnove GIS-tehnologij // Rossijskaya sel'skohozyajstvennaya nauka. 2019. № 1. P. 66-70.

10. Zavodchikov N. D., Speshilova N. V., Taspaev S. S. Ispol'zovanie nejrosetevyh tehnologij v prognozirovanii jeffektivnosti proizvodstva zerna // Iz-vestiya Orenburgskogo gosudarstvennogo agrarnogo universiteta. 2015. № 1 (51). P. 216-219.

11. Zaharova R. V., Gajnutdinov I. G. Primenenie bespilotnogo letatel'nogo apparata pri desikacii maslichnyh kul'tur // Vektor jekonomiki. 2018. № 11 (29). P. 118.

12. Zvereva V. I., Voroncov A. A. Iskusstvennye nejronnye seti i geoinformacionnye tehnologii v sel'skom hozyajstve // Sovremennye innovacionnye tehnologii podgotovki inzhenernyh kadrov dlya gornoj promyshlennosti i transporta. 2019. № 1 (6). P. 191-196. 
13. Ispol'zovanie glubokih svjortochnyh nejronnyh setej dlya avtomaticheskogo vydeleniya prepyatstvij na vzletno-posadochnoj polose po dannym vidimogo i infrakrasnogo diapazona / V. V. Knyaz' [i dr.] // Nauchnaya vizualizaciya. 2017. V. 9. № 4. P. 89-96.

14. Kashirina I. L., Demchenko M. V. Issledovanie i sravnitel'nyj analiz metodov optimizacii, ispol'zuemyh pri obuchenii nejronnyh setej // Vestnik VGU. Sistemnyj analiz i informacionnye tehnologii. 2018. № 4. P. 123-132.

15. Mihajlenko I. M., Timoshin V. N. Jekspertnye sistemy programmnogo upravleniya $\mathrm{V}$ tochnom zemledelii // Vestnik rossijskoj sel'skohozyajstvennoj nauki. 2020. № 2. P. 11-16.

16. Mihajlenko I. M. Razvitie metodov i sredstv primeneniya dannyh distancionnogo zondirovaniya zemli v sel'skom hozyajstve // Tendencii razvitiya nauki i obrazovaniya. 2018. № 41-3. P. 70-83.

17. Mihajlenko I. M. Upravlenie agrotehnologiyami i robotizirovannye i robotizirovannye sredstva realizacii // Innovacii v sel'skom hozyajstve. 2019. № 1 (30). P. 242-258.

18. Modelirovanie nejroupravleniya skorost'yu dozhdeval'nyh mashin / D. A. Solov'ev [i dr.] // Agrarnyj nauchnyj zhurnal. 2020. № 7. P. 81-84.

19. Monitoring posevov ozimoj pshenicy s primeneniem bespilotnoj a]rofotos'emki i opticheskogo datchika GreenSeeker RT200 / S. V. Zhelezova [i dr.] // Vestnik Orenburgskogo gosudarstvennogo universiteta. 2016. № 6. P. 56-61.

20. Nikolenko C., Kadurin A., Arhangel'skaya E. Glubokoe obuchenie. SPb.: Piter, 2018. 480 p.

21. Primenenie ajerofotos'jomki $\mathrm{s}$ primeneniem mul'tispektral'noj kamery $\mathrm{v}$ komplekse $\mathrm{s}$ nejroset'yu v sel'skom hozyajstve / A. S. Sych [i dr.] // Chronos. 2019. № 9 (36). P. 26-28.

22. Primenenie mul'tispektral'noj ajerofotos'jomki v komplekse $\mathrm{s}$ nejroset'yu dlya avtomatizacii monitoringa v sel'skom hozyajstve / V. A. Dolzhenko [i dr.] // Naukoemkie tehnologii i innovacii (XXIII nauchnye chteniya): sbornik dokladov Mezhdunarodnoj nauchno-prakticheskoj konferencii, posvyaschennoj 65-letiyu BGTU im. V. G. Shuhova. 2019. P. 33-37.

23. Rogachev A. F. Melihova E. V., Belousov I. S. Issledovanie razvitiya i produktivnosti sel'skohozyajstvennyh kul'tur s primeneniem bespilotnyh letatel'nyh apparatov // Izvestiya NV AUK. 2020. № 3 (59). P. 397-406.

24. Rogachev A. F., Melihova E. V. Obosnovanie algoritmov i instrumentariya dlya nejrosetevogo prognozirovaniya urozhajnosti agrokul'tur $\mathrm{s}$ ispol'zovaniem retrospektivnyh dannyh // Izvestiya NV AUK. 2020. №1. P. 290-302.

25. Sulejmanov S. R., Loginov N. A. Perspektiva ispol'zovaniya distancionnogo zondirovaniya zemli i BPLA v sel'skom hozyajstve Tatarstana // Vestnik Kazanskogo gosudarstvennogo agrarnogo universiteta. 2017. V. 12. № 4 (46). P. 17-19.

26. Teoriya i tehnologii upravleniya orosheniem sel'skohozyajstvennyh kul'tur na osnove informacionnyh tehnologij podderzhki prinyatiya reshenij i matematicheskogo modelirovaniya / $\mathrm{K}$. E. Tokarev [i dr.] // Izvestiya NV AUK. 2020. № 4 (60). P. 433-448.

27. Faktornyj analiz dannyh po urozhajnosti rannego kartofelya v polevom opyte i obrabotka rezul'tatov imitacionnogo modelirovaniya / V. V. Borodychev [i dr.] // Izvestiya NV AUK. 2020. № 2 (58). P. 404-419.

28. Cherevatova T. F., Ermolaeva O. S. Iskusstvennyj intellekt: diagnostika boleznej rastenij po raspoznavaniyu izobrazhenij // Jekonomika i predprinimatel'stvo. 2021. № 2 (127). P. 980-985.

29. Yun G. N., Medinskij D. V. Primenenie bespilotnyh letatel'nyh apparatov v sel'skom hozyajstve // Nauko€mni tehnologiï. 2017. V. 36. № 4. P. 35-41.

30. Bashkirov O. A., Bravermann E. M., Muchnik I. B. Potential function algorithms for pattern recognition learning machines // Automation and Remote Control. - 1964. - N 25. - P. 629-631.

31. Bian, X., Chen, C. Fusing local and global features for high-resolution scene classification // IEEE J. Sel. Topics Appl. Earth Observ. Remote Sens. 2017. V. 10 (6). P. 2889-2901.

32. Cheng G., Li Z. Remote sensing image scene classification using bag of convo-lutional features // IEEE Geosci. Remote Sensing Lett. 2017. V. 14 (10). P. 1735-1739.

33. Chlingaryan A., Sukkarieh S., Whelan B. Machine learning approaches for crop yield prediction and nitrogen status estimation in precision agriculture: A review // Comput. Electron. Agricult. 2018. Vol. 151. P. 61-69.

34. Deep convolutional neural networks for hyperspectral image classification / W. Hu [et al.] // Journal of Sensors. 2015. V. 2015. No. 258619. 


\section{***** H3BECTYЯ ***** \\ НИЖНЕВОАЖСКОГО АГРОУНИВЕРСИТЕТСКОГО КОМПАЕКСА: \\ НАУКА И ВЫСШЕЕ ПРОФЕССИОНААЬНОЕ ОБРАЗОВАНИЕ}

35. Estimation of condition of cultivated pastures under remote sensing of earth / V. I. Trukhachev // Engineering for Rural Development Proceedings. 2019. P. 442-449.

36. Fukushima K. Neocognitron: A self-organizing neural network model for a mechanism of pattern recognition unaffected by shift in position // Biol. Cybern. 1980. V. 36. No. 4. P. 193-202.

37. Goodfellow I. Deep Learning (Adaptive Computation and Machine Learning series) // The MIT Press. 2016. Nov. P. 800.

38. Hebb D. O. The Organization of Behavior: A Neuropsychological Theory. New York: Wiley, 1949. $358 \mathrm{p}$.

39. Kadhim V. A., Abed M. H. Convolutional Neural Network for Satellite Image Classification // Studies in Computational Intelligence. 2020 P. 165-178.

40. Kitonsa H., Kruglikov S. V. Significance of drone technology for achievement of the united nations sustainable development goals // R-Economy. 2018. V. 4. № 3. P. 115-120.

41. Khaki, Wang L. Crop yield prediction using deep neural networks // Frontiers Plant Sei. 2019. Vol. 10. P. 621.

42. Krizhevsky A., Sutskever I., and Hinton G., Imagenet classification with deep convolutional neural networks // Advances in Neural Information Processing Systems (NIPS). Lake Tahoe. NV, USA, 2012. P. 1097-1105.

43. Machine learning in agriculture: A review / K. G. Liakos [et al.] // Sensors. 2018. Vol. 18. No. 8. P. 2674.

44. Melikhova E.V. Information system and database for simulation of irrigated crop growing / Melikhova E.V., Rogachev A.F., Skiter N.N. // Studies in Computational Intelligence. 2019. T. 826. C. 1185-1191.

45. Recent Advances in Remote Sensing for Crop Growth Monitoring [Tekst] / Cheng, T.; Yang, Z.; Inoue, Y.; Zhu, Y.; Cao, W. Preface // Remote Sens. - 2016. -№ 8. - P. 116.

46. Review of modern technologies intellectual decision support in the reclamation of agricultural crops / Tokarev K.E., Nekrasova T.N., Popova O.V., Lebed N.I. // IOP Conference Series: Earth and Environmental Science. 2. Cep. "Mathematical Modeling of Technical and Economic Systems in Agriculture II" 2020. C. 012023.

47. Rogachev A. F., Melikhova E. V., Shokhnekh A. V. Monitoring and economic \& mathematical modeling of manufacture and consumption of agricultural products as a tool of food security management // Espacios. 2018. V. 39. № 1. P. 1.

48. Rosenblatt F. The Perceptron: A probabilistic model for information storage and organization in the brain // Psychological Review. 1958. N 65. P. 386-408.

49. Simonyan K., Vedaldi A., Zisserman A. Deep inside convolutional networks: visualizing image classification models and saliency maps. arXiv preprint arXiv:1312.6034, 2013.

50. Vegetative indices dynamics modeling based on multispectral distant monitoring data analysis / Tokarev K.E. // IOP Conference Series: Earth and Environmental Science. 3. Cep. "Mathematical Modeling of Technical and Economic Systems in Agriculture III-2020" 2021. C. 012038.

51. Understanding deep learning requires rethinking generalization / C. Zhang, S. Bengio, M. Hardt, B. Recht, O. Vinyals // Cornell University Library. 2016.

\section{Author information:}

Tokarev Kirill Evgenievich, associate Professor of the Department of Mathematical modeling and computer science, Volgograd state agricultural university (Russia, 400002, Volgograd, Universitetskiy Ave., 26), tel. 8 (8442) 41-17-10, e-mail: tke.vgsha@mail.ru.

Rudenko Andrey Yurevich, associate Professor of the Department of Mathematical modeling and computer science, Volgograd state agricultural university (Russia, 400002, Volgograd, Universitetskiy Ave., 26), tel. 8 (8442) 41-17-10, e-mail: rudenkovgsxa@mail.ru.

Kuzmin Vsevolod Alexandrovich, teacher of the Department of Mathematical modeling and computer science, Volgograd state agricultural university (Russia, 400002, Volgograd, Universitetskiy Ave., 26), tel. 8 (8442) 41-17-10, e-mail: pniiemt.kuzmin@yandex.ru.

Chernyavsky Alexey Nikolaevich, assistant of the Department of electrical Equipment and electrical management of agricultural enterprises, Volgograd state agricultural university, Russia, 400002, Volgograd, Universitetskiy Ave., 26), tel. 8 (8442) 41-11-27, e-mail: alexei.tcherniawsckij@yandex.ru. 


\title{
Информация об авторах
}

Токарев Кирилл Евгеньевич, доцент кафедры «Математическое моделирование и информатика», ФГБОУ ВО Волгоградского ГАУ (РФ, 400002, г. Волгоград, пр-т Университетский, 26), кандидат экономических наук, тел. 8 (8442) 41-17-10, e-mail: tke.vgsha@mail.ru.

Руденко Андрей Юрьевич, доцент кафедры «Математическое моделирование и информатика», ФГБОУ ВО Волгоградского ГАУ (РФ, 400002, г. Волгоград, пр-т Университетский, 26), кандидат экономических наук, тел. 8 (8442) 41-17-10, e-mail: rudenkovgsxa@mail.ru.

Кузьмин Всеволод Александрович, преподаватель кафедры «Математическое моделирование и информатика», ФГБОУ ВО Волгоградского ГАУ (РФ, 400002, г. Волгоград, пр-т Университетский, 26), кандидат экономических наук, тел. 8 (8442) 41-17-10, e-mail: pniiemt.kuzmin $@$,yandex.ru.

Чернявский Алексей Николаевич, ассистент кафедры Электрооборудование и электрохозяйство предприятий АПК, тел. 8 (8442) 41-11-27, e-mail: alexei.tcherniawsckij@yandex.ru.

DOI: 10.32786/2071-9485-2021-04-43

ANALYSIS OF LOAD DETERMINATION METHODS AT AGRICULTURE PRODUCTION ENTERPRISE

\author{
D.A. Desyatnichenko', Yu.V. Daus², I.V. Yudaev² \\ ${ }^{1}$ Azov-Black Sea Engineering Institute, \\ «Don State Agrarian University», Zernograd \\ 2" "St. Petersburg State Agrarian University", Pushkin, St. Petersburg
}

Received 11.03.2021

Submitted 30.11.2021

\section{Summary}

The article systematizes data on methods for calculating electrical loads. Analysis of various approaches to determining the load is presented on the example of real Agricultural Enterprise «Plant Sorghum» of the Federal State Budget Scientific Center «Agrarian Scientific Center «Donskoy», located in Zernograd of Rostov region. Comparative analysis of the predicted and actual graphs of the electric load of the research object is carried out.

\begin{abstract}
Introduction. In the context of urgent necessity to support, develop, and restore the agro-industrial complex, the search for new energy sources that would meet the requirements of the introduced high-tech processes is most relevant for rural areas characterized by shortage of free capacities. At the forefront there are photovoltaic systems for converting solar energy, which are distinguished by the relative simplicity of the technology for generating electrical energy, environmental friendliness, ease of operation and maintenance. When justifying the parameters of photovoltaic power plant for agricultural facilities, special attention should be paid to the available initial information (list and capacity of power consumers, load schedules of the entire enterprise or each outgoing line from the substation switchgear separately, etc.), since this will affect the final power of the solar field and storage or backup devices. Object. The object of the study is the power supply system of the real Agricultural Enterprise «Plant - Sorghum» of the Federal State Budget Scientific Center «Agrarian Scientific Center «Donskoy», located in Zernograd of Rostov region. Materials and methods. For electrical consumers of the Agricultural Enterprise «Plant - Sorghum», annual and daily schedules of electrical load were calculated and constructed in three ways: by the calculation method, by the methodology of the guidelines and experimentally. Results and conclusion. Each considered method of determining the load of agricultural consumer has its own characteristics. The most accurate load monitoring method takes a long time to collect information. The guidelines methodology is the easiest to use and requires minimum of initial information, but its application in choosing the parameters of photovoltaic power plants can lead to underutilization of the available solar energy potential of the studied geographic point, which is especially significant in the summer period when the maximum intensity of solar radiation and the greatest workload of agricultural enterprises are observed. The use of the calculation method for constructing consumer load graphs is also associated with the collection of wide range of initial information. But the data predicted by the calculation method give a significant overestimation of the power consumption, which can lead to overestimation of the installed capacity of the photovoltaic power plant and excessive capital costs, and subsequently the need to utilize the excess generated electrical energy.
\end{abstract}

